\title{
Political Leadership, Conflict and the Prospects for Constitutional Peace*
}

\author{
Colin Jennings \\ The Queen's College \\ University of Oxford \\ Oxford, OX1 4AW \\ United Kingdom \\ colin.jennings@queens.ox.ac.uk
}

\begin{abstract}
The emphasis in constitutional political economy has been that new rules and institutions can be devised that improve the welfare of a society. Given the number of societies that are infected with political conflict and as a result lower levels of welfare, this paper attempts to analyze why we do not see more constitutional conventions aimed at eliminating conflict. The key idea is that expressively motivated group members may create incentives for instrumentally motivated group leaders such that it leads them to choose conflict rather than compromise. Nonetheless, it is not argued that such a peace is impossible to obtain. This leads to a further question, that if such a constitutional agreement could be found, would the expressive perspective alter the conventional instrumental perspective on the sort of constitutional reform that should be undertaken?

Key words: Leadership, Conflict, Constitution

JEL Classification numbers D72, D74
\end{abstract}

* I would like to thank Alan Hamlin, Roger Congleton, Amihai Glazer, Iain McLean and participants at the Public Choice Society meeting in Nashville, 2003 and the European Public Choice Society meeting in Aarhus, 2003 for their helpful comments. 


\section{Introduction}

Buchanan (1975) conceived of two distinct stages in constitutional choice, the constitutional contract and the post-constitutional contract. The constitutional contract is the agreement among individuals to emerge from a state of anarchy and form a government which will protect the rights that have been agreed upon in the constitutional contract. The basis for constitutional agreement is that peace will provide an improvement in welfare for all individuals relative to anarchy. The post-constitutional contract is then built upon the security of rights, so that free trade can flow among citizens and that government institutions are formed to provide public goods. The two welfare enhancing roles of government (relative to anarchy) are captured in Buchanan's (1975) distinction between the protective and productive state and this field of study is termed Constitutional Political Economy (CPE).

The normative focus of CPE is that institutions should exist such that the welfare of the members of society lie on the Pareto frontier. That is, no individual could be made better off without making someone else worse-off. The challenge for the political economy component of CPE has been in identifying political failures in the Paretian sense of inefficiency and providing reasons for the existence of such inefficiency, or as Acemoglu (2003) phrased it, "Why not a Political Coase Theorem?." The challenge for the constitutional component of CPE is to devise institutional arrangements that would eliminate the inefficiency. ${ }^{1}$

The concentration of work in CPE has been upon identifying inefficiencies and possible constitutional reform in the post-constitutional contract. That this has been the focus is unsurprising. CPE has been developed with mainly western democratic societies in mind. In these societies the initial constitutional contract or escape from anarchy, could be viewed as basically settled. ${ }^{2}$ While the cost of inefficient policy due to problems with the post-constitutional contract may be serious, no more serious example of the failure of a Political Coase Theorem exists than the persistence of violent conflict. This obviously

\footnotetext{
${ }^{1}$ See Mueller (1996) for a comprehensive survey of both aspects.

${ }^{2}$ Nonetheless, a significant rational choice literature on conflict exists. See Usher (1992) and the collection of papers in Garfinkel and Skaperdas (1996). A general focus of this literature is to analyze the decision to invest in predation and/or defense in order to steal and/or protect resources, at the expense of production and as a result the welfare of a society.
} 
applies to many societies and a common source of the inability to forge a constitutional agreement would appear to be conflicting group identities. We argue that in predominantly group based societies a political equilibrium can exist with a relatively high level of political conflict. This implies an inefficient political outcome and the normative claim for constitutional reform aimed at reducing conflict becomes very strong.

Buchanan's analysis suggests that if individuals are rational such reform should be attainable. He discusses how coalitions may form out of pure anarchy (where conflict is Hobbesian, with each individual fighting against and protecting themselves from every other individual), but suggests that the costs of conflict between coalitions should eventually lead to agreement on a common enforcing agent or protective state. In effect, coalitions should converge through a series of constitutional conventions. One could view this as coalition leaders simply explaining the high costs of conflict to their group members, who would in turn approve a constitution designed to eliminate conflict. The group members are conceived as thinking instrumentally and recognizing that their approval of a peace agreement will, in fact, lead to a peace agreement and the realization of gains from trade.

So in principle, the leaders should be able, through negotiation, to end the conflict and devise mutually acceptable institutions for governance and thus both be made better off. In practice, such movement to efficiency (or a Political Coase Theorem) is dogged with obstacles. Cowen (2004) provides a comprehensive list of potential difficulties and then applies them to the Arab-Israeli conflict. Three key difficulties are transaction costs, a lack of binding enforcement or commitment and 'nested' games. Transaction costs are the costs of trading, most notably bargaining costs. The problem of lack of enforcement to bind a possible agreement is given prominence in Fearon (2004). Once an agreement is signed, there may be an incentive for one or both of the parties to renege without redress and awareness of this prevents an agreement being signed in the first place. Nested games refer to games that may be hidden within the ostensible game, for instance, contests for leadership within groups.

Obviously transaction costs and lack of binding enforcement are serious problems, but in this paper we will assume that they do not exist. We shall assume that bargaining is 
costless and that there is sufficient trust between leaders or there is a willingness to engage a third party such that leaders may forge a binding agreement. This is done so that attention can be drawn to a quite different source of political failure. This lies within the realm of nested games and concerns the problems that expressive choice (fuelled by group identity) poses for achieving agreements that provide political efficiency.

The distinction between instrumental and expressive choice is as follows. The instrumental approach is the application of standard economic reasoning when individuals are decisive with regard to outcomes. Individuals are depicted as choosing as though they actually determine political outcomes and this approach to modeling political choice has been the dominant one in Political Economics. The expressive approach recognizes that the likelihood of being decisive in large group decision making is effectively zero and thus something other than the prospect of determining political outcomes may be motivating political action. Political action may simply be an expression of identity on the part of the political actor, and this expression may run contrary to a choice that would have been made instrumentally. Furthermore, this is completely rational as the expressive choice is in keeping with the nature of large group decision making. ${ }^{3}$

Therefore, group members are free to choose in whatever manner they find most directly appealing. In the context of this paper, we view expressive political choices as creating two particular obstacles to peace. First, group members may expressively select leaders who are more extreme than they would have chosen instrumentally. Second, group members may expressively choose to be more group active in times of conflict rather than peace although they may not have made this choice instrumentally. They may do this because they feel that more extreme leaders are more representative of group ideology and/or that they feel more attached to group identity when the group is in conflict.

So expressive preferences allied with group allegiance may make peace very difficult to achieve, but we do not argue that it is impossible. Rather, we argue that for peace to be achieved a clear demonstration of the costs of conflict may not be sufficient. Expressive

\footnotetext{
${ }^{3}$ For detailed discussions regarding the logic of expressive choice and its application to stable western style democracies see Brennan and Lomasky (1993), Brennan and Hamlin (1999) and Schuessler (2001).
} 
opinion would have to swing behind the idea of peace. Recognition of this shifts our attention away from post-constitutional contract to the prior stage of constitutional contract. We stress that there is a considerable difference between the idea of peace and the idea of constitutional peace. The first might simply be a cease-fire, where the institutions in a society are the same as when there was conflict. The idea of a constitutional peace is in keeping with the central message of CPE, that to realize efficiency the constitutional rules of the game need to be changed. So the issue is how to design institutions to maintain and institutionalize peace. We are interested as to how the acknowledgment of expressive preferences as central to the analysis may affect the design of such institutions.

The paper is organized as follows. In section 2 we provide a very simple game of political interaction to be played by two group leaders. We demonstrate that when group activity is significantly greater under conflict than compromise all potential leaders will find it in their interests to choose conflict rather than peace. However, when the excess rents from conflict are not too excessive, the incentives to engage in conflict will be greater for extremists than moderates. Nonetheless, despite conflict being an equilibrium strategy for extremists they will still have an incentive to form a constitutional peace. In section 3, under the assumption that a constitutional convention does take place, we discuss generally the area of institutional design in the context of resolving group conflict and we link it to the debate in conflict resolution regarding consociation versus integration. In section 4 we draw some conclusions from the analysis.

\section{The Game of Political Interaction}

We depict the interaction of two group leaders which have been selected out of two preexisting groups. ${ }^{4}$ They are faced with the choice of engaging in conflict or compromise. In addition to the acquisition of political control, office rents are available as a payoff to

\footnotetext{
${ }^{4}$ See Hamlin and Jennings (2004) for a model of group formation under instrumental and expressive motivations.
} 
group leadership. It is through the selection of group leaders and the determination of office rents that we aim to demonstrate the significance of the expressive preferences of the group members for the instrumental choices facing group leaders.

\subsection{The Game of Political Interaction}

Whichever leaders emerge in each group, they will find themselves playing a game against the opposing leader which will determine the overall political outcome. The political outcome is a combination of the distribution of political power and possible costs of conflict. There will also be rents available to the leaders which are dependent upon the nature of group interaction.

\section{Leader 2}

Compromise

(COMP)

$\begin{aligned} \text { Leader } 1 & \text { comprom } \\ & \text { (COMP) }\end{aligned}$

conflict (CONF) conflict

(CONF)

$(1-k)\left(L_{1}-L_{2}\right)+\pi^{m}, k\left(L_{1}-L_{2}\right)+\pi^{m} \quad\left(L_{1}-L_{2}\right)+\pi^{m}, \pi^{v}-v$

$\pi^{v}-v,\left(L_{1}-L_{2}\right)+\pi^{m}$

$(1-x)\left(L_{1}-L_{2}\right)+\pi^{v}-v, x\left(L_{1}-L_{2}\right)+\pi^{v}-v$

Figure 1 The Game of Political Interaction

We assume that all members of society are members of one of the two groups, and that the members of society are distributed uniformly across locations on $[0,1]$. So we could imagine this to be a distribution of ideological or ethnic beliefs with the most extreme members of the opposing groups located at 0 and $1 . L_{1}$ and $L_{2}$ are the leaders of group 1 and 2. Group 1 contains $[0, k)$ members of the population and group $2(k, 1]$ where we assume that $\frac{1}{2} \leq k \leq 1$ so that we model group 1 as of equal size or greater than group 2 and group size reflects the relative strength of the two groups. We assume that mutual compromise reflects the relative size of the groups. To capture the idea that stronger 
groups may win more political power than is reflected in the size of their group, $\mathrm{x}$ tells us the distribution of political power when there is group conflict and $x \geq k . v$ is the cost of conflict.

$\pi^{v}$ stands for office rent to the leaders when engaged in conflict, $\pi^{m}$ stands for office rent to the leaders when seeking compromise and $\pi^{v}>\pi^{m}$. The assumption is that group members find group activity more expressively attractive when the group is in conflict than in peace. We assume that group activity is positively correlated with office rents, so conflict generates higher rents than compromise. The phenomenon of an opposing outside group strengthening internal group identity and in turn, contributions within the group is analyzed by Takacs (2001). This also fits with a recent paper by Glaeser (2005) which explores the idea of a market for hatred. In the context of this paper, group leaders can be perceived as earning rents through supplying hatred. The demand for hatred comes from expressively motivated group members who obtain their feeling of group identity through conflict with the other group. Since no single individual can bring about group conflict, the negative impact upon instrumental interests may play no role in their calculus. Finally, in addition to the game depicted, an outside option exists, given by $(1-\alpha)\left(L_{1}-L_{2}\right), \alpha\left(L_{1}-L_{2}\right)$ which is the distribution of power agreed constitutionally. This implies (in keeping with the CPE tradition) that players are able to step outside the game they are in and devise a new set of rules. Such a constitution ends the game and a set of peaceful institutions are agreed. It may be that such a constitution confirms the distribution of power that would have been the case if the leaders could have played compromise, in which case, $\alpha=k$. However, since the constitution is likely to be devised to solve conflict and that conflict may have been highly favorable to the stronger group in terms of the distribution of power, it may be that $\alpha>k$.

We assume Nash equilibrium play and (CONF, CONF) will be the unique equilibrium if

$$
\pi^{v}-\pi^{m}-v>(1-x)\left(L_{1}-L_{2}\right)
$$

and

$$
\pi^{v}-\pi^{m}-v>x\left(L_{1}-L_{2}\right)
$$

However, since by assumption $(1-x)\left(L_{1}-L_{2}\right)>x\left(L_{1}-L_{2}\right)$ only (1) needs to be satisfied 
to ensure mutual conflict. The higher are the rents from conflict and the selection of more extreme leaders make (1) more likely to hold.

\subsection{Profitable conflict for leaders}

The first point to note is that if $\pi^{v}-\pi^{m}>v$ conflict will exist in equilibrium regardless of the location of the group leaders. Furthermore, this is the Pareto superior outcome from the perspective of the leaders. To see this note that the joint payoff from (CONF, CONF) is higher than any of the other possible outcomes when $\pi^{v}-\pi^{m}>v$. As a result, there is no incentive for them to negotiate a constitutional peace as there will be no gains from trade to be made. Note that the superior outcome from the point of view of the leaders does not carry through for ordinary group members. The existence of conflict as an outcome may provide a much lower utility than would be the case under constitutional peace, but it is the preference of the population for greater group participation when there is conflict rather than when there is peace that causes the politically inferior outcome. We do not depict this behavior as irrational, but say rather that a negative externality exists. Since an individual choice does not determine the outcome, individuals do not consider the negative effect that their choice may have and focus only on the extra direct, expressive benefits they obtain from being more group active in times of conflict.

A discussion of the issue of profitable conflict and countries where the phenomenon has existed can be found in Williams $(2003,185-89)$. The analysis presented here is somewhat related to papers by Hess and Orphanides (1995 and 2001). They also are interested in situations where a political leader will select conflict as a strategy. They explain that a leader in a democracy may choose conflict if he or she is low in economic competence and thus by displaying an ability to conduct a war they may be re-elected and continue to enjoy office rents. The key difference is that in their papers, voters may choose instrumentally for a leader conducting a war on the basis of perceived competence in that area. In this paper, group members provide a leader with rents through activity rather than votes and for reasons unrelated to actual political outcomes. The analysis also relates to Collier (2000) who argued that conflict may bring private returns in the form of revenue from organized crime and thus reduce the incentive to end conflict. 
It also relates to the more generally focused analysis of Acemoglu (2003). He argues that the failure to achieve a Political Coase Theorem is related to the politically powerful choosing policies that benefit themselves, but which impose costs on the rest of society such that overall welfare is lower than that which would be possible. Acemoglu then asks why those who are current losers cannot compensate those who are current winners from the movement to an efficient outcome, thus leaving all parties better off. He believes that an inability to form binding agreements between political elites and citizens lies at the core of a failure to achieve efficient trade. While the focus on the politically powerful benefiting at a cost to society is echoed in this paper, the source of failure is different. In the setting depicted here, even if a binding agreement could be made with any sub-group that would set up among the citizens (assuming they can overcome obvious free-rider problems) with the aim of ending the conflict and compensating the leaders from the surplus, the same expressive logic that is driving the conflict in the first place persists. While group members may know that contributing to this group would be in their best interests ex post, if they feel their contribution is insignificant the expressive appeal of supporting their own group in current conflict may be more alluring than supporting moderation. In this way, expressive logic provides an extra reason for why the Political Coase Theorem may fail. It may fail because political efficiency is an ex post consequentialist concept, but the nature of ex ante political decision-making (which determines political consequences) is usually made in large group settings and thus less amenable to instrumental/consequentialist reasoning.

\subsection{Expressive Constitutionalism}

The previous section related the existence of conflict to the possibility of leaders earning excess rents from conflict. This provides the first expressive story, that group members may be more group active in conflict than peace. The second expressive story is that group members may expressively select extremists. This is significant for the case in which $\pi^{v}-\pi^{m}<v$. An inspection of (1) shows that conflict will not exist for leaders located close to each other, so conflict can only exist in equilibrium if groups select relatively more extreme leaders. 
For $\pi^{v}-\pi^{m}<v$, (COMP, COMP) is now the Pareto optimal outcome for leaders, since the joint payoff is higher than for any of the other possible outcomes. An instrumental perspective would suggest that although extremist leaders will fight in equilibrium they will see that (in the absence of transaction costs or commitment problems) there are gains from trade. They would be able to achieve a distribution of power $\alpha$ that leaves both parties better off. What sort of obstacles may prevent the new institutions and perhaps the convention itself from taking place? One obstacle is that if the convention must be ratified by referendum then that referendum will be an expressive choice and there is no guarantee that group members will vote for the constitution (Brennan and Hamlin (2002)). If members choose expressively for conflictual leaders then it is likely that they will vote against peace. Leaders may worry that losing a referendum would lead to their downfall as leaders and thus the forfeit of office rents. If this is the case (as in the previous subsection) the nature of expressive preferences may prevent a convention from taking place. The difference now is that leaders would not be dependent upon a citizen group offering compensation, to be made better off. It is directly within their own grasp, subject to securing the support of their respective groups. Note though, that this problem would not have emerged if voters had not expressively selected extreme leaders to begin with.

One might argue that the position of leader in itself may carry expressive value to group members, so there may be room for the leader to argue for peace, modify the expressive preferences of the members and thus win the referendum. Overall, the leaders must weigh up the uncertain payoff arising from attempting to persuade group members to support a constitutional peace versus the certain payoff of maintaining leadership by choosing conflict.

The discussion in this paper links to the argument made by Voigt (1998) for a positive rather than a normative approach to constitutional economics. He argues that the formal institutions embodied in a constitution are the result of an evolutionary process of group bargaining where the nature of bargaining is determined to a large extent by the internal institutions of the participants. By internal institutions Voigt means informal rules, of which in the context of this paper group norms are an example. Here we argue that the conditions for constitutional peace are determined by the nature of group interaction, so 
that group hostility may be such that leaders may find it either profitable to engage in conflict or that finding a peace may be too risky for a leader to even attempt. Internal institutions may prevent welfare-enhancing external institutions to be created or reformed.

\section{What Sort of Constitutional Peace?}

Leaders may gamble that their position carries sufficient weight to carry any peace proposal, or perhaps specific points in time may reduce the expressive desire for conflict thus opening the path to a peace. A constitutional convention is possible and peace is possible, but what sort of peace? Would any peace be little more than a cease-fire, so that hostilities would resume once war-weariness has passed? Or will the peace be lasting in the sense that a constitution is designed with the purpose of changing the underlying behavior of group members. ${ }^{5}$

The CPE perspective is that change within a society can be implemented by shifting from in-period political choice to constitutional political choice. Constitutional choice is an attempt to design institutions that provide new 'rules of the game' for in-period politics. These new rules alter the conditions under which individuals play the political game, and the aim is to provide rules that make the outcomes of the game 'better'. In the context of this paper, 'better' means the elimination of political conflict. To agree to a cease-fire at a constitutional convention does not change the nature of the game, so it would be expected that hostilities are very likely to resume at a certain point. The key is to design institutions that provide for a resolution of the conflict and a binding commitment to a new set of institutions.

Designing institutions for the purpose of conflict resolution is clearly an area of extreme complexity which will be dependent on the specific circumstances facing a particular conflictual society. Before entering into a more specific discussion of constitutional design, we argue that two conditions must be met for any constitutional proposal to be successful. These conditions follow directly from the analysis in this paper.

\footnotetext{
${ }^{5}$ On a related theme see Grossman (2004).
} 
First, those taking part in the constitutional convention must agree. The delegates at the convention (which we argue would be the leaders of the conflicting groups) must believe that any constitutional arrangements that may be forged must leave them better off instrumentally. This reflects the contractarian normative basis for CPE. Second, any proposal must be expressively appealing to group members. This reflects the feasibility of constitutional reform in that those who lead the groups are likely to be the delegates at the constitutional convention and their position as group leaders after the convention is dependent upon the support of their members. This means that a proposal that would have been acceptable to all members of society at an instrumental level may not be acceptable to all at the expressive level. To that end, the proposal must be more than a cease-fire. The rules for political interaction must actually change and the goal must be to lessen the negative effects of group identity as displayed through the expressive choices of group members.

Can these two conditions lead us to say something more concrete? We give two examples. First, consider a proposal by a strong group leader to offer Coaseian style compensation to a weak group in return for almost hegemonic control by the strong group. While this may be of instrumental appeal to the weak group leader it is difficult to see how such a proposal could ever be expressively acceptable to the members of the weak group. An awareness of the significance of expressive preferences reduces the set of possible constitutions as it must pass two conditions rather than one. It must be instrumentally appealing to the leaders and it must be expressively appealing to group members.

A second example of constitutional design that may pass the two conditions outlined above, but would not normally be expected to pass a purely instrumental conception of constitutionalism would be the formation of what appear to be merely symbolic institutions. Symbolic institutions could be viewed as institutions that serve very little practical function and thus do not impact on the reality of the distribution of power between groups. Generally, we might think that constitutional design would focus on the elimination of unproductive bureaucracy. If we consider a society infected with identity based political conflict, we may alternatively conclude that creating unproductive institutions may actually lessen the effect of hostile expressive desires if group members 
feel that these institutions in some way represent them. In this paper we have focused on the social dilemma that arises when the expressive preference for group hostility provides political conflict, although political conflict is an inferior outcome ex post. If at the root of the group hostility lie grievances regarding the representativeness of a society's institutions, then the creation of symbolic institutions may provide some degree of 'existence value' to expressively motivated group members. Again, note that these institutions do not necessarily have to play any significant functional role with regard to providing public goods. Indeed, given the argument of bureaucratic waste, it may be better that they do not, in fact, have access to significant funds.

This argument applies directly to the debate concerning consociation versus integration. ${ }^{6}$ At a basic level, a consociational approach takes group identity as given and devises a constitutional agreement that incorporates this fact. Four components are identified; an inclusive executive, a legislature elected by proportional representation, group autonomy where possible and minority vetoes on issues of vital interest. Integration theory suggests that consociational constitutional agreements are doomed since they set in stone the source of conflict, that is, the group identities themselves.

This paper contributes to the debate by taking an even stronger consociational line than the one outlined above. The components outlined above could be viewed as a settlement which is instrumentally appealing to group leaders. However, once they are aware that any settlement must be expressively appealing to group members, the arrangements may not go far enough in satisfying expressive group identity. Therefore, further symbolic institutions are required to sell an agreement to their respective groups.

To give a concrete example, the Belfast Agreement of 1998 contained three strands. The first relates to the internal arrangements, in the spirit of the components outlined above such as an all-inclusive executive and a legislature elected by the singletransferable vote. The second and third strands address external arrangements, the second relating to the North-South Ministerial Council and the third relating to the British-Irish Council. The extent to which the second and third external strands play a significant role

\footnotetext{
${ }^{6}$ This is not the place to review this debate in detail. For an overview of theories of conflict resolution see O'Leary and McGarry (1995). Consociational theory stems from Lijphart (1969). For an application of the consociation/integration debate applied to Northern Ireland and the Belfast Agreement, see chapters 1 to 6 in McGarry (2001) and Horowitz (2002).
} 
in the actual governance of Northern Ireland and determination of outcomes therein is debatable, but they certainly play a less prominent role than the institutions created in the internal strand (when, of course, the Northern Ireland Assembly is operating). It could be argued that the North-South Ministerial Council is an important symbolic institution for the nationalist community and the British-Irish Council (an institution that would bring together the states of the UK and Ireland alongside the devolved governments within the $\mathrm{UK}$ ) is an important symbolic institution for the unionist community. In this sense, the Belfast Agreement could be viewed as an expressive constitution, one in which the institutions created provide a continuing focus for expressive choice, but a choice that is more likely to achieve peace. ${ }^{7}$

\section{Conclusion}

This paper has attempted to provide a prominent role for expressive motivation as an explanation for the inability of some societies to forge a constitutional peace. If expressive preferences lead to a much higher level of group activity and as a consequence much higher office rents for leaders, then all potential leaders will find conflict profitable. Even when conflict is not as profitable, if groups were to select more extreme leaders conflict remains a possibility. Although gains from agreements are available, extremist leaders may appreciate that such an agreement is expressively unappealing to group members and thus would not attempt to pursue peace. If they were to successfully risk achieving peace, the line of reasoning taken in this paper may lead us to consider recommending institutions that are considerably different (or additional) to those that may be recommended under an approach that views the primary cause of this political failure as a failure of group leaders to agree. More is required than leaders to agree. An

\footnotetext{
${ }^{7}$ The North-South Ministerial Council provides an all-Ireland institutional link thus explaining its appeal to nationalists. The British-Irish Council is appealing to unionists on two levels. First the government of the Irish Republic is outnumbered within the Council by the governments of and within the UK. Second, in any future united Ireland a direct link would be maintained institutionally with the UK. See chapter 3 by O'Leary in McGarry (2001) for a discussion of the role of these external institutions.

Another possible example of an important 'symbolic institution` are truth and reconciliation commissions as instituted in South Africa and El Salvador (Williams (2003, 273-276). These are important in allowing the antagonistic groups to feel that justice for past acts is seen to be done and thus lessen the urge to support a return to violence out of a lingering desire for revenge.
} 
agreement must also be expressively appealing to group members and this may require the creation of institutions that would not be necessary if group members were to make choices in an instrumental manner, as though their choices are decisive.

Finally, although this paper has been focused purely on the role of expressive motivation in sustaining inefficient conflict, a further agenda is implied. One might ask whether expressive motivation has a role to play in accounting for the persistence of political failures more generally. In any large group setting (which is most of politics) one might suspect that it does. 


\section{References}

1. Acemoglu, D. (2003) Why Not a Political Coase Theorem? Social Conflict, Commitment and Politics. Journal of Comparative Economics, 31: 620-52.

2. Brennan, G., Hamlin, A. (1999) On Political Representation. British Journal of Political Science, 29 : $109-27$

3. Brennan, G., Hamlin, A. (2002) Expressive Constitutionalism. Constitutional Political Economy, 13 : 299-311.

4. Brennan, G., Lomasky, L. (1993) Democracy and Decision. Cambridge University Press, Cambridge

5. Buchanan, J. (1975) The Limits of Liberty: Between Anarchy and Leviathan. University of Chicago Press, Chicago

6. Collier, P. (2000) Rebellion as a Quasi-Criminal Activity. Journal of Conflict Resolution, 44: 839- 53.

7. Cowen, T. (2004) A Road Map to Middle Eastern Peace? A Public Choice Perspective. Public Choice, 118: 1-10.

8. Fearon, J. (2004) Why do some civil wars last so much longer than others? Journal of Peace Research, 41: 275-302.

9. Garfinkel, M., Skaperdas, S. (eds.) (1996) The Political Economy of Conflict and Appropriation. Cambridge University Press, Cambridge

10. Glaeser, E. (2005) The Political Economy of Hatred. Quarterly Journal of Economics, 120, 45-86.

11. Grossman, H. (2004) Constitution or Conflict?' Conflict Management and Peace Science, 21: 29- 42.

12. Hamlin, A., Jennings, C. (2004) Group Formation and Political Conflict: Instrumental and Expressive Approaches. Public Choice, 118: 413-35.

13. Hess, G., Orphanides, A. (1995) War Politics: An Economic, Rational-Voter Framework. American Economic Review, 85: 828-46.

14. Hess, G., Orphanides, A. (2001) War and Democracy. Journal of Political Economy, 109: 776-810.

15. Horowitz, D. (2002) Explaining the Northern Ireland Agreement: The Sources of an Unlikely

Constitutional Consensus. British Journal of Political Science, 32: 193-220.

16. Lijphart, A. (1969) Consociational Democracy. World Politics, 21: 207-25.

17. McGarry, J. (ed.) (2001) Northern Ireland and the Divided World: Post-Agreement Northern Ireland in Comparative Perspective. Oxford University Press, Oxford

18. Mueller, D. (1996) Constitutional Democracy. Oxford University Press, Oxford

19. O'Leary, B., McGarry, J. (1995) Regulating Nations and Ethnic Communities. In Breton, A.,

Galeotti, G., Salmon, P., Wintrobe, R. (eds.), Nationalism and Rationality. Cambridge University

Press, Cambridge

20. Schuessler, A. (2001) A Logic of Expressive Choice. Princeton University Press, Princeton

21. Takacs, K. (2001) Structural Embeddedness and Intergroup Conflict. Journal of Conflict Resolution, 45: 743-69. 
22. Tollison, R. (1996) Rent Seeking. In: Mueller, D. (ed.) Perspectives on Public Choice. Cambridge University Press, Cambridge

23. Usher, D. (1992) The Welfare Economics of Markets, Voting and Predation. Manchester University Press, Manchester

24. Voigt, S. (1999) Explaining Constitutional Change: A Positive Economics Approach. Edward Elgar, Cheltenham

25. Williams, R. (2003) The Wars Within: People and states in conflict. Cornell University Press, Ithaca. 